East African Medical Journal Vol. 83 No. 4 April 2006

PREVALENCE OF VISUAL IMPAIRMENT AND BLINDNESS IN A NAIROBI URBAN POPULATION

L.K. Ndegwa, MPHE (K.U), HCS, HD (Ophth), DCM\&S (Nbi), Lecturer, Department of Ophthalmology, Kenya Medical Training College, P.O. Box 2377-00202, Nairobi, Kenya, J. Karimurio, MBChB, MMed (Ophth) (UoN), MSc (CEH) (London), Lecturer, Department of Ophthalmology, College of Health Sciences, University of Nairobi, P.O. Box 1967600202, Nairobi, Kenya, R.O. Okelo, PhD, MSc, B.Ed (Science), Lecturer, Department of Biological Sciences, Kenyatta University, P.O. Box 43844-00100, Nairobi, Kenya and H.S. Adala, MBChB, MMed (Ophth) (UoN), DO,RCS (London), Consultant Eye Surgeon/Technical Advisor, Sight First Programme, LCIF, P.O. Box 19676-00202, Nairobi, Kenya

Request for reprints to: Mr. L.K. Ndegwa, Department of Ophthalmology, Kenya Medical Training College, P.O. Box 2377-00202, Nairobi, Kenya

\title{
PREVALENCE OF VISUAL IMPAIRMENT AND BLINDNESS IN A NAIROBI URBAN POPULATION
}

\author{
L.K. NDEGWA, J. KARIMURIO, R.O. OKELO and H.S. ADALA
}

\begin{abstract}
Objective: To determine the prevalence and causes of visual impairment and blindness among Kibera slum dwellers.

Design: Population based Survey.

Setting: Kibera Slums, Kibera Division, Nairobi, Kenya.

Subjects: One thousand four hundred and thirty eight randomly selected slum dwellers.

Results: The prevalence of blindness and visual impairment was $0.6 \%$ (95\% CI: 0.21 to 1.0$)$, and $6.2 \%(95 \%$ CI: 4.95 to 7.15$)$ respectively. $37.5 \%$ of those found blind were due to cataract followed by refractive errors $25.0 \%$. $58.1 \%$ of those with visual impairment had refractive errors while $35.5 \%$ had cataracts. Females had a higher prevalence of visual impairment compared to males but the difference was not statistically significant $(P=0.104)$.

Conclusions: Prevalence of blindness in Kibera slums is slightly lower than the estimated national average $(0.7 \%)$ while that of visual impairment is almost three times higher. The leading causes of blindness are cataract followed by refractive errors. For visual impairment, refractive error was the leading cause followed by cataract.

Recommendation: Kibera slum dwellers are in need of comprehensive eye care services offering cataract surgery and low cost spectacles.
\end{abstract}

\section{INTRODUCTION}

Inequalities in health mirror inequalities in socioeconomic status (1). The WHO estimates that there are 50 million blind people in the world of whom 1.5 million are children below 16 years (2). Globally, 135 million people have visual impairment and are in need of social, vocational, economic or rehabilitative support services $(3,4)$. Almost $90 \%$ of the world's blind live in developing countries (5).

Kibera Division of Nairobi Province has the oldest (6) and largest city slum $\left(223.4 \mathrm{Km}^{2}\right)$ in Kenya (7). The Division is divided into seven administrative locations: Kibera, Laini Saba, Serangombe, Mugumoini, Langata, Karen, and Nairobi West. Laini Saba, Kibera, and Serangombe, are slums covering $2.4 \mathrm{Km}^{2}$ and housing about $13.37 \%$ of Nairobi population. They are congested $\left(1,284\right.$ persons per $\left.\mathrm{Km}^{2}\right)$ and poorly accessible. Their inhabitants have mixed cultures and beliefs. Kenyatta National and Mbagathi District Hospitals have well equipped eye clinics and neighbours Kibera. Kikuyu Eye Unit and Loresho Lions Eye Hospital are about ten kilometres from Kibera. There are many privately owned clinics, nursing homes, and traditional medical practitioners in the area. 


\section{MATERIALS AND METHODS}

A population based survey conducted between November 2002 and January 2003. The minimum sample size was statistically determined. The ethics committee of Kenyatta University, Nairobi, approved the study. Training and testing of survey team was done. Data collection tools (WHO/PBL/ 88.1 eye examination record form, with modifications to accommodate local spectrum of eye disorders) were field-tested. Two stage cluster random sampling method was adopted. The study subjects were residents aged two years and above. Those under two years were excluded because they need special examination set-up. It was assumed that the number of children below two years with visual impairment and blindness is too low to significantly affect the study results. Consent was taken, demographic data recorded, and ophthalmic examination done (Figure 1). Snellens visual acuity charts, trial set were used. Blindness was defined as presenting visual acuity of less than $3 / 60$ in the better eye. Visual impairment was defined as presenting visual acuity of less than $6 / 18$ but equal to or better than $3 / 60$ in the better eye. The data were analysed and associations with factors like age, sex and education was determined using the SPSS for windows version 10.0.

\section{RESULTS}

Of the eligible 1,588 subjects, 1,478 (93.08\%) turned up for the study. A few had their visual acuity and history taken but could not wait for ophthalmic examination; ending up with a study population of 1,438. A total of $1,302(90.5 \%)$ subjects had formal education: $983(68.4 \%)$ primary, $287(20 \%)$ secondary and $32(2.2 \%)$ had college level. One hundred and forty six $(10.2 \%)$ of the subjects were in permanent employment, 313(21.8\%) were in small-scale business like selling vegetables, fruits, charcoal and second hand clothes and $68.1 \%$ were dependants (Table 1 ).

The prevalence of visual impairment was $6.2 \%$ (89 subjects, 95\% CI: $4.95-7.15 \%$ ) while of blindness was $0.6 \%$, (95\% CI: $0.21-1.0 \%)$. Females had higher odds of having visual impairment than males (Odds ratio $0.778 ; 95 \% \mathrm{Cl}: 0.507-1.194)$. The prevalence of visual impairment was significantly higher in the younger ( $<50$ years) than in the older subjects $(4.1 \%$ and $2.6 \%$ respectively, $\mathrm{p}=0.000)$. There was significant difference between education and prevalence of blindness $(\mathrm{p}=0.000)$.

The prevalence of visual impairment (VI) due to refractive error was 3.6\% (95\%, CI: $2.6 \%-4.6 \%$ ) and cataract $2.2 \%(95 \%, \mathrm{CI}: 2.95 \%-1.44 \%)$. Cataract was the major cause of blindness, $(37.3 \%)$, refractive errors two (25\%).

Blindness due to cataract was significantly higher among the females compared to males $(25 \%$, $95 \%$ CI $5.00 \%-55.0 \%)$ and males $(12.5 \%$, $95 \%$ CI $10.42 \%-35.42 \%)$. The prevalence of visual impairment was significantly higher among the unemployed subjects compared to those who were employed ( $4.0 \%$ vs $2.7 \%$; $\mathrm{P}=0.067$ ).

Figure 1

Examination of subjects

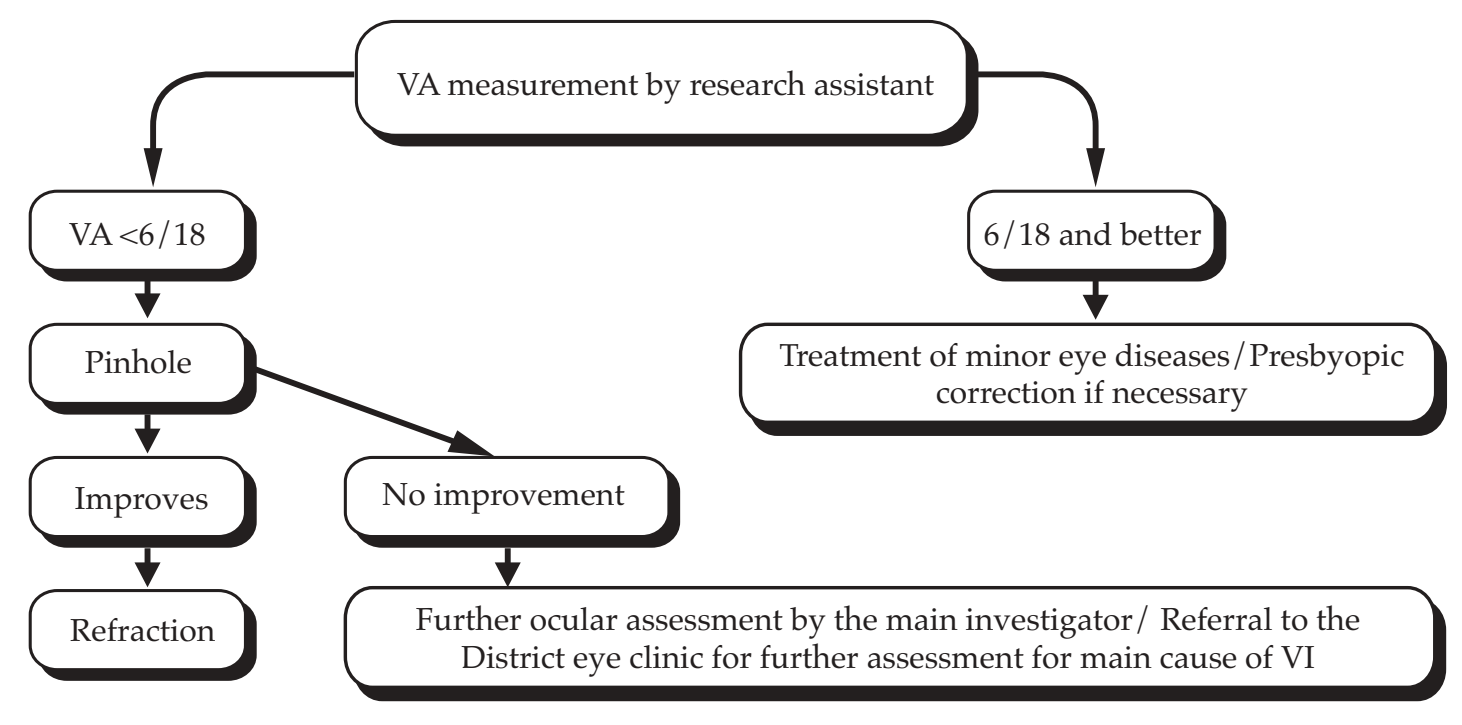


Table 1

Demographic associations with blindness of subjects

\begin{tabular}{|c|c|c|c|c|}
\hline \multirow[t]{2}{*}{ Characteristic } & \multirow{2}{*}{$\begin{array}{c}\text { Total group } \\
\text { No. }\end{array}$} & \multicolumn{2}{|c|}{ Subjects' Blind $Y$} & \multirow[t]{2}{*}{ Statistics } \\
\hline & & No. & $(\%)$ & \\
\hline \multicolumn{5}{|l|}{ Age (years) } \\
\hline 0-9 & 445 & 2 & $(0.5)$ & \\
\hline $10-19$ & 264 & 1 & $(0.4)$ & $X^{2}=58.119$ \\
\hline $20-29$ & 294 & 0 & $(0)$ & $\mathrm{df}=9$ \\
\hline $30-39$ & 178 & 1 & $(0.6)$ & $P=0.000$ \\
\hline $40-49$ & 127 & 0 & $(0)$ & \\
\hline $50-59$ & 66 & 2 & $(3.0)$ & \\
\hline $60-69$ & 27 & 1 & $(3.7)$ & \\
\hline $70-79$ & 16 & 0 & $(0)$ & \\
\hline $80-89$ & 4 & 1 & (25) & \\
\hline Unknown (age not stated) & 17 & 0 & (0) & \\
\hline Total & 1438 & 8 & $(0.6)$ & \\
\hline \multicolumn{5}{|l|}{ Sex } \\
\hline Male & 599 & 5 & $(0.8)$ & $X^{2}=1.438$ \\
\hline Female & 839 & 3 & $(0.4)$ & $\mathrm{df}=1$ \\
\hline Total & 1438 & 8 & $(0.6)$ & $\mathrm{P}=0.230$ \\
\hline \multicolumn{5}{|l|}{ Education } \\
\hline Primary & 983 & 4 & $(0.4)$ & \\
\hline Secondary & 287 & 1 & $(0.3)$ & \\
\hline College & 32 & 0 & $(0)$ & $X^{2}=1.944$ \\
\hline Never been to school & 70 & 2 & $(2.9)$ & $\mathrm{df}=4$ \\
\hline Under age & 66 & 1 & (1.5) & $\mathrm{P}=0.746$ \\
\hline Total & 1438 & 8 & $(0.6)$ & \\
\hline \multicolumn{5}{|l|}{ Economic activity } \\
\hline Employed & 146 & 0 & (0) & \\
\hline Not employed & 421 & 5 & $(1.2)$ & $X^{2}=5.599$ \\
\hline In business & 313 & 0 & $(0)$ & $\mathrm{df}=3$ \\
\hline In school/under age & 558 & 3 & $(0.5)$ & $\mathrm{P}=0.133$ \\
\hline Total & 1438 & 8 & $(0.6)$ & \\
\hline
\end{tabular}

\section{DISCUSSION}

The proportion of females in the study population was high compared to that of males in the source population $(58.3 \%$ vs $41.7 \%)$, but not statistically significant $(\mathrm{P}=0.190)$. This compares to studies done in Oman and India, which reported $91.8 \%$ and $87.3 \%$ respectively $(8,9)$.

The prevalence of blindness and visual impairment was $0.6 \%$ and $5.8 \%$ respectively, comparable to a study done in India, which reported $50 \%$ (8). Appling this rate to the Kibera slum population of 183,263 then 1,100 individuals are blind and 11,362 visually impaired in Kibera. The prevalence of blindness varied a lot in various age groups, from zero to nine years $(0.45 \%)$ to 80 to 89 years $(25 \%)$. This significant difference shows that there is a strong relationship between blindness and age. The Oman eye study documented that blindness increases dramatically with age; $93 \%$ of the blind were in the age of 40 years and older in the study population (9). The prevalence of blindness among the unemployed was $0.6 \%$. Possibly, because the unemployed were elderly who 
had decreased expectations in life (10). The data suggest that the burden of VI in Kibera is ten times higher than that of blindness. Possibly, because, the study population is socially and financially disadvantaged owing to their living conditions (slums), hence they cannot access the eye care services (11) offered in the city clinics and hospitals.

The prevalence of VI in females was 1.4 times that of males, but this difference was not statistically significant ( $p>0.005)$. Moser (7), has reported similar results $(8.0 \%$ vs $5.9 \%)$ in Bioko, Guinea. Females compared with males had higher odds of having VI (OR $=0.778 ; 95 \%$ CI 0.507-1.194).

Among the younger age groups, uncorrected refractive error was the main cause of VI. A study in Malaysia reported $88 \%$ of the population $<50$ years of age, had refractive error as the main cause of VI (12). Refractive error has also been reported as a significant cause of VI from the developed world $(13,14)$.

The survey revealed that the target groups for interventions in reducing cataract prevalence were people older than 50 years of age and females, while for refractive errors they were young adults, and females together with the unemployed.

Resources, both material and financial, are severely limited in developing countries where most people live beyond the reach of health and social services. The per capita income (US \$) in less developed countries is below US $\$ 635$, compared with US $\$ 7911$ or more, in the more developed nations. A critical stage of economic development may exist whereby the prevalence of preventable blindness becomes significantly less. Potentially, the economic development in nations and /or regions with a per capita income of less than US $\$ 2000$ could dramatically reduce the impact of preventable blindness (15).

\section{ACKNOWLEDGEMENTS}

The authors acknowledge the contribution of the field research assistants: Joseph Njoroge, Jane Njoki, Caesar Odhiambo, Juliet Makau, Ann Kioi, Jennifer Seki, James Gichuru, Geoffrey Gitau and Lucy (Christian child fund staff). Dr. Mwangi, Ophthalmologist, Miriam and Njue the O.C.Os and nurses of Mbagathi District Hospital eye clinic for their support and assisting in examination and confirming of the diagnosis. The Director KSB for providing drugs and other materials for this study. The Administration of Kibera: the DO, chiefs, assistant chiefs, and the village elders. The staff of Kenyatta University, Department of Biological Sciences.

\section{REFERENCES}

1. Frenk J., Gakidou E.E. and Murray C.J.L. East-West Centre, Population and Health Studies. Bulletin W.H.O Intern. J. Public Health. 1999; 7: 537-616.

2. WHO. Blindness and visual impairment. General information. 1997.

3. Thylefors, B. A global initiative for elimination of avoidable blindness. J. Comm. Eye Health. 1998; 11: 1-3.

4. WHO. Prevention of blindness. 2001.

5. Thylefors, B; Negrel, A.D and Pararajasegaram, E. Global data on blindness. Bull. World Health Organ. 1995; 73: 115 -121.

6. Government of Kenya, Immunisation coverage, Kibera. Kenya Expanded programme on Immunisation. $\mathrm{MOH} /$ Medicos Son Frontiers, Nairobi. 1996; Dec. 1.

7. Moser C.L., Baranera M.M., Vega F., et al. Survey of blindness and visual impairment in Bioko, Equatorial Guinea. Brit. J. Ophthalmol. 2002; 86: 257-260.

8. Dandona R., Dandona L., Srinivas M., et al. Moderate visual impairment in India: the Andhra Pradesh eye disease study. Brit. J. Ophthalmol. 2002; 86: 373-377.

9. Khandekar R., Mohammed A.J., Negrel A.D. and Riyami A.A.I. The prevalence and causes of blindness in the Sultanate of Oman: The Oman eye study (OES). Brit. J. Ophthalmol. 2002; 86: 957-962.

10. Smeeth L. and Iliffe S. Effectiveness of screening older people for impaired vision in community setting: systemic review of evidence from randomised controlled trials. Brit. J. Ophthalmol. 1998; 28: 660-663.

11. Ndegwa L.K., Karimurio J., Okelo R.O. and Adala H.S. Barriers to utilisation of eye care services in Kibera slums in Nairobi, Kenya. East Afr. Med. J. 2005; 82: 24-26.

12. Zainal M., Ismail S.M., Ropilah A.R., et al. Prevalence of blindness and low vision in Malaysian population: results from the National Eye survey 1996. Brit. J. Ophthalmol. 2002; 86: 951-956.

13. Rahmani B., Tielsch J.M. and Katz J. The cause specific prevalence of visual impairment in an urban population: The Baltimore eye survey. Ophthalmol. 1996; 103: 1721-1726.

14. Attebo K., Mitchell P. and Smith W. Visual acuity and causes of visual field loss in Australia: The blue mountains eye study. Ophthalmol. 1996; 103: 357-364.

15. Schwab R.I. and Viet H.H. Social economic development in the prevention of global blindness. Brit. J. Ophthalmol. 2001; 85: 653-657. 